\title{
INTESTINAL CANDIDASIS CAUSING SUB ACUTE SMALL BOWEL OBSTRUCTION: A RARE CASE
}

Patibandla Hemanth ${ }^{1}$, Namburi Amulya², Md. Jawed Akhter³ ${ }^{3}$ Laxmi Venkatesh ${ }^{4}$

\section{HOW TO CITE THIS ARTICLE:}

Patibandla Hemanth, Namburi Amulya, Md. Jawed Akhter, Laxmi Venkatesh. "Intestinal Candidasis Causing SubAcute Small Bowel Obstruction: A Rare Case". Journal of Evolution of Medical and Dental Sciences 2015; Vol. 4, Issue 73, September 10; Page: 12783-12786, DOI: 10.14260/jemds/2015/1839

\begin{abstract}
Immunodeficiency is increasingly encountered in daily medical practice. As a result, the concomitant risk for opportunistic infections is higher. Immuno-compromised patients may present with uncommon clinical and radiologic conditions. We report a case of 48-year-old man chronic alcoholic for 25yrs who presented with abdominal pain and features suggestive of small bowel obstruction. On exploratory laparotomy and enterostomy yellow, shaggy necrotic material adherent to the folds of intestine was found. After the histopathological confirmation extensive fungal enteritis due to Candida albicans with partial small bowel obstruction was diagnosed.
\end{abstract}

KEYWORDS: Sub acute, Small bowel obstruction, Intestinal candidiasis.

INTRODUCTION: Candida organisms commonly colonize the human gastrointestinal tract as a component of the resident microbiota. Their presence is generally benign. The relative rarity of intestinal candidiasis as sole cause of intestinal obstruction in conjunction with lack of definitive imaging findings makes its preoperative diagnosis difficult and is usually based on histopathological findings after surgical exploration. Therefore it can be considered as one of the differential diagnosis in immunocompromised patients presenting with features of intestinal obstruction.

CASE REPORT: A 48 yrs. old male patient presented with pain abdomen since 7 days insidious in onset, diffuse and colicky type all over the abdomen with constipation and bilious vomiting about five to seven episodes/day. He was a chronic alcoholic since 25 years. Patient was thin built and illnourished with features of dehydration. Blood pressure at presentation was $90 / 60 \mathrm{~mm}$ of $\mathrm{Hg}$ with tachycardia. Abdomen was distended with no visible peristalsis, tenderness all over the abdomen with guarding. Tympanic note was heard all over the abdomen with absence of shifting dullness and sluggish bowel sounds. Rectum was empty. Blood investigations showed elevated leucocyte count 18,700 with neutrophilia (92\%) and dyselectrolytemia. Values for few significant investigations were, Sodium-120meq/dl, Calcium-5.9mg/dl, Hypoproteinemia-3.8gm/dl and Hypoalbuminemia-1.7 $\mathrm{mg} / \mathrm{dl}$. Viral markers were negative. X ray abdomen PA view was suggestive of subacute bowel small bowel obstruction [Figure 1].

Patient was resuscitated, electrolyte imbalance was corrected. He was taken for exploratory laparotomy. At laparotomy dilated ileal and jejunal loops with a transition in the distal ileum followed by clear collapse of distal segment without any intra-abdominal adhesions were noted. Contents couldn't be milked past the transition point and inspissated stools were noted in the jejunum and ileum. On enterotomy we noted the luminal surface of the small bowel was covered with yellow, shaggy material adherent to the folds, consistent with candida and necrotic material [Figure 2] and [Figure 3]. Material was sent for histological examination and loop ileostomy was done [Figure 4]. 
Histological report after 5 days came out to be candida albicans and patient was treated then with intravenous fluconazole only stopping antibiotics. Postoperatively there was persistent hypocalcaemia and hypoproteinemia even on repeated correction. Patient didn't respond and succumbed to death on $17^{\text {th }}$ post-operative day due to sepsis mostly due to candidemia.

DISCUSSION: Candida albicans is an important opportunistic pathogen in immunocompromised individuals and may cause a wide range of diseases; from superficial mucocutaneous infections to life threatening disseminated systemic candidiasis.(1) Populations at risk for serious disseminated disease include immunosuppressed patients such as cancer patients particularly leukemia patients, diabetics, chronic alcoholics and transplant recipients.(2) Our patient was chronic alcoholics for 25 years.

Prolonged treatments with broad-spectrum antibiotics for any cause destroy the indigenous intestinal microbiota, which provokes intestinal Candida albicans proliferation and adversely affects the immunological system.(3) In systemic candidemia inoculation is thought to originate from the gut, where the organism is frequently found as a component of the normal flora. Even though it is commonly found as a commensal, candida enteritis causing acute intestinal obstruction had been very rarely reported.

Preoperative diagnosis requires a high degree of suspicion as ultrasonography would be nonspecific except in the disseminated phase. CT shows dilated bowel loops, thickening of the bowel wall along with high density content in the involved segment of the intestine. Definite diagnosis requires either the identification of candida organisms within inflammatory lesions. Tissue samples obtained with laparoscopy or laparotomy are often necessary to make the diagnosis since percutaneous biopsies are more prone to sampling error.(4)

Candidiasis is treated with intravenous fluconazole at $12 \mathrm{mg} / \mathrm{kg}$ loading dose followed by maintenance dose of $6 \mathrm{mg} / \mathrm{kg}$ for 2 weeks along with diet rich in proteins and deficient in carbohydrates. The outcome after an acute infection with Candida can vary from resolution of the neutropenia and favorable response to therapy to persistent neutropenia and death due to overwhelming infection, despite therapy.(5) Over all the prognosis of systemic candidemia is poor with deaths reported even after 39 days of treatment.(4)

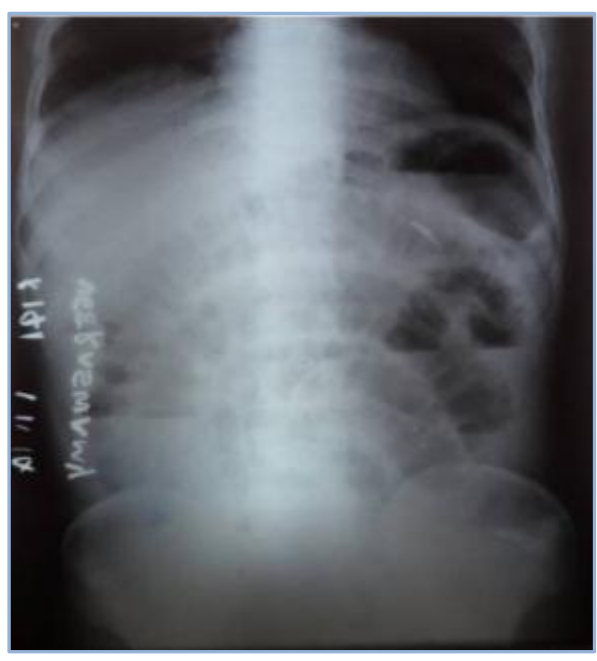

Fig. 1: Abdomen PA view

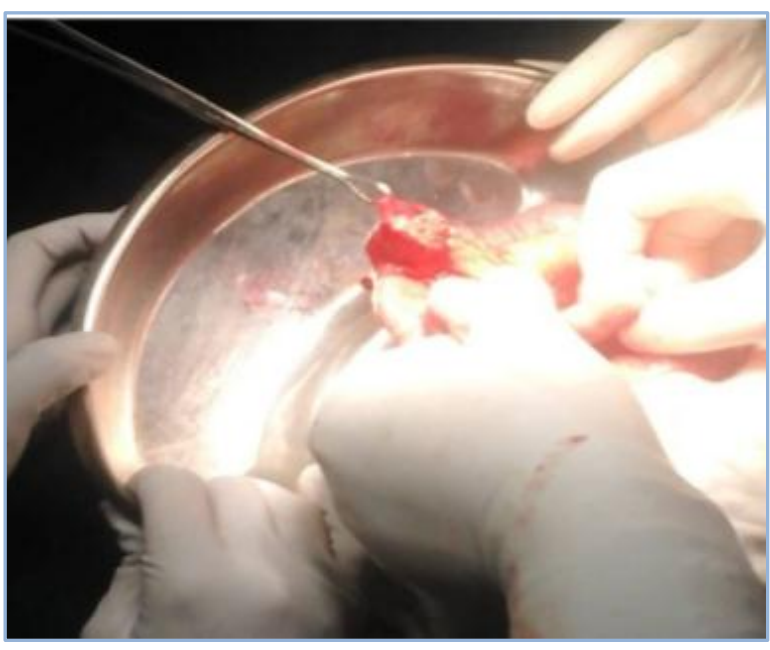

Fig. 2: Enterotomy showing candidial element 


\section{CASE REPORT}

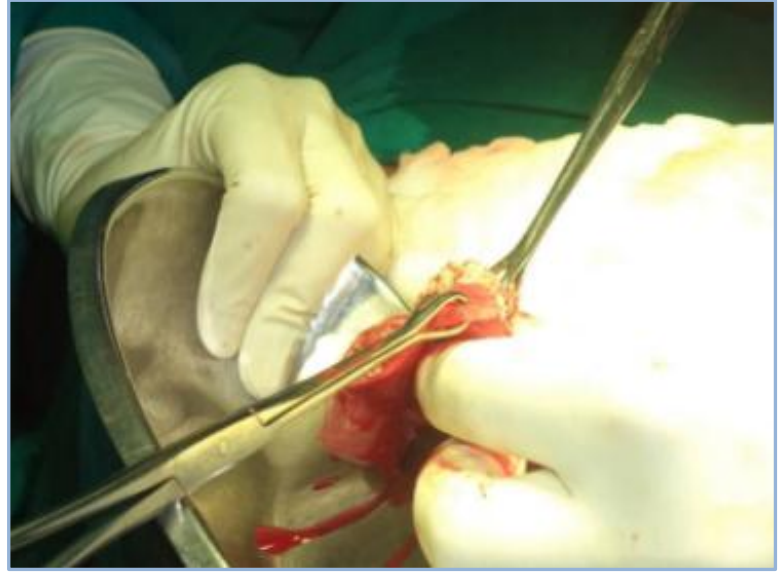

Fig. 3: Enterotomy showing candidial element

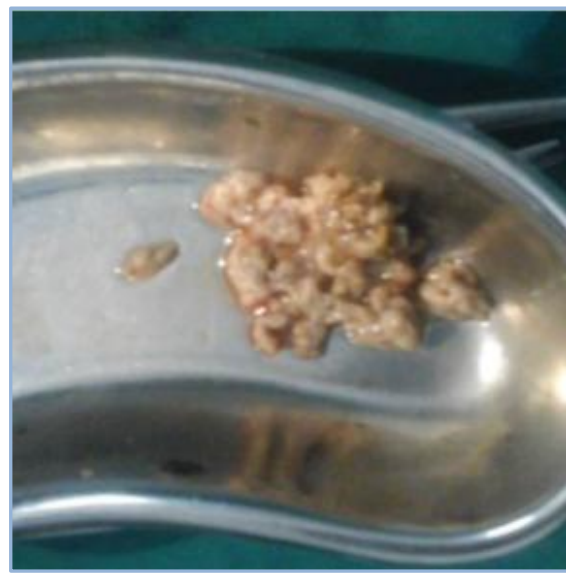

Fig. 4: Candidial Element

\section{REFERENCES:}

1. Small intestinal bacterial overgrowth syndrome, Jan Bures, Jiri Cyrany, Darina Kohoutova, Miroslav Förstl, Stanislav Rejchrt, Jaroslav Kvetina, Viktor Vorisek, Marcela Kopacova , World J Gastroenterology 2010 June 28; 16(24): 2978-2990 .

2. Intestinal Lesions Associated with Disseminated Candidiasis in an Experimental Animal Model Karl A. Andrutis, Perry J. Riggle, Carol A. Kumamoto, Saul Tzipori j. Clin. Microbiol. June 2000vol. 38 no. 6 2317-2323.

3. Intestinal candidiasis. A clinical report and comments about this opportunistic pathology. RuizSanchez, Calderon-Romero, Sanchez-Vega JT, Tay J Mycopathalogia, 2002;156(1):9-11

4. Small bowel obstruction secondary to disseminated candidiasis in an immunocompromised patient: radiologic pathologic correlation. D. Bielen, K. Mortelé, H. Peters, D. Lombard, P. Ros JBR-BTR, 2005, 88: 20-22.

5. Kontoyiannis D.P., Luna M.A., Samuels B.I., Bodey G.P.: Hepatosplenic candidiasis. A manifestation of chronic disseminated candidiasis. Infect Dis Clin North Am, 2000, 14: 721-739. 


\section{CASE REPORT}

\section{AUTHORS:}

1. Patibandla Hemanth

2. Namburi Amulya

3. Md. Jawed Akhter

4. Laxmi Venkatesh

\section{PARTICULARS OF CONTRIBUTORS:}

1. Post Graduate, Department of General Surgery, Mamata Medical College, Khammam, Telengana.

2. Post Graduate, Department of General Surgery, Mamata Medical College, Khammam, Telengana.

3. Professor, Department of General Surgery, Mamata Medical College, Khammam, Telengana.

FINANCIAL OR OTHER COMPETING INTERESTS: None
4. Post Graduate, Department of General Surgery, Mamata Medical College, Khammam, Telengana.

\section{NAME ADDRESS EMAIL ID OF THE CORRESPONDING AUTHOR:}

Md. Jawed Akhter, Department of General Surgery, Mamata Medical College, Khammam-507002, Telengana.

E-mail: dr_mdjawedakther@yahoo.com

Date of Submission: 27/08/2015.

Date of Peer Review: 28/08/2015.

Date of Acceptance: 05/09/2015.

Date of Publishing: 10/09/2015. 